\title{
Does High Public Trust Amplify Compliance with Stringent COVID-19 Government Health Guidelines? A Multi-country Analysis Using Data from 102,627 Individuals
}

This article was published in the following Dove Press journal:

Risk Management and Healthcare Policy

\section{Anton Pak' \\ Emma McBryde' \\ Oyelola A Adegboye $\mathbb{D}^{1,2}$}

'Australian Institute of Tropical Health and Medicine, James Cook University, Townsville, QLD, Australia; ${ }^{2}$ Public Health \& Tropical Medicine, College of Public Health, Medical and Veterinary Sciences, James Cook University,

Townsville, QLD, Australia
Correspondence: Oyelola A Adegboye Public Health \& Tropical Medicine, College of Public Health, Medical and Veterinary Sciences, James Cook University, I James Cook Drive Townsville, Queensland 48I4, Australia Email oyelola.adegboye@jcu.edu.au
Purpose: To examine how public trust mediates the people's adherence to levels of stringent government health policies and to establish if these effects vary across the political regimes. Methods: This study utilizes data from two large-scale surveys: the global behaviors and perceptions at the onset of COVID-19 pandemic and the Oxford COVID-19 Government Response Tracker (OxCGRT). Linear regression models were used to estimate the effects of public trust and strictness of restriction measures on people's compliance level. The model accounted for individual and daily variations in country-level stringency of preventative measures. Differences in the dynamics between public trust, the stringent level of government health guidelines and policy compliance were also examined among countries based on political regimes.

Results: We find strong evidence of the increase in compliance due to the imposition of stricter government restrictions. The examination of heterogeneous effects suggests that high public trust in government and the perception of its truthfulness double the impact of policy restrictions on public compliance. Among political regimes, higher levels of public trust significantly increase the predicted compliance as stringency level rises in authoritarian and democratic countries.

Conclusion: This study highlights the importance of public trust in government and its institutions during public health emergencies such as the COVID-19 pandemic. Our results are relevant and help understand why governments need to address the risks of noncompliance among low trusting individuals to achieve the success of the containment policies.

Keywords: public trust, stringency, compliance, SARS-CoV-2, COVID-19, public health

\section{Introduction}

Compliance to public health policies and regulations is critical to people's health, particularly in the time of an infectious disease crisis such as the ongoing COVID19 pandemic. To contain the spread of COVID-19, governments around the world have implemented a variety of movement restrictions and quarantine measures as well as issued public health recommendations. However, the effectiveness of the government response to the pandemic largely depends on the level of citizens' compliance in following public health advice, especially while pharmaceutical interventions and vaccines are still under development or not widely available. 
Adherence to the recommended government health guidelines (eg preventative measures such as social distancing, avoidance of mass gatherings, usage of masks and better hygiene practices) is critical to arrest the rapid growth of COVID-19 spread and avoid stringent lockdown, as well as associated economic and health costs. Higher compliance levels also help health systems to cope with increasing demand for health services, which is particularly relevant to the countries with weaker health systems and lower health-care capacity. However, despite the various preventative measures and public health regulations that have been implemented and largely standardized around the world, the compliance levels between and within countries differ significantly. Thus, understanding what drives this heterogeneity in compliance is essential to the success of the policy interventions and public health strategy.

Previous research on compliance during this and past infectious disease epidemics show that individuals who have a high perception of risks of being infected and experience negative health consequences are more likely to comply with government restrictions and public health guidelines. ${ }^{1,2}$ In addition, societal response and adherence to regulations and public health guidelines are often dependent on the level of public trust in government and its institutions. ${ }^{3-6}$ This is not surprising as public trust is central to the legitimacy of government's decisions, ${ }^{7,8}$ especially in cases when the individual liberties (eg lockdowns, curfews, travel movements) are restricted in order to protect society and manage the health crisis more effectively. In this regard, the literature suggests that trusting residents who are more likely to accept the government's decisions and follow public health guidelines better than distrusting individuals. ${ }^{4,9}$

The recent outbreak of Ebola in Democratic Republic of Congo in 2018-2019 provides a vivid example of how a broad environment of distrust makes it difficult to combat the spread of the disease due to poor compliance despite the availability of vaccines and significant international and local efforts. ${ }^{10}$ The widespread belief in misinformation about Ebola virus disease and low levels of trust in government institutions were strongly associated with limited effectiveness of public health response such as compliance with social and behavioral recommendations, refusal to seek medical care and acceptance of vaccines. ${ }^{10}$

Emerging empirical evidence from the COVID-19 pandemic also supports this positive relationship between trust in government measures and compliance levels, showing the importance of high trust levels in achieving success with public health interventions. ${ }^{3,5,11}$

Differential compliance may also be driven by the stringency measures and how individuals and companies perceive the costs and benefits of following government policies. For example, public health recommendations of wearing masks, following frequent hand washing practices and maintaining social distancing during the COVID-19 pandemic do not impose high costs on individuals. They are likely to be complied with, while stay-at-home orders and mobility restrictions carry a more significant burden on the public, especially in developing countries where economic and health resilience is mostly constrained. Yet, prolonged stringent government restrictive measures are challenging to maintain as defiance and resistance to restrictions can build up, and evidence-based justification and transparent communication become critical to convincing citizens to continue to comply. The impact of stringency on compliance may also be compounded by the level of trust in government - due to the people's belief as to whether the governors are acting in the best interest of the governedand the high public trust possibly reinforces compliance behavior in response to the rising level of restrictions.

There has been a growing debate as to whether the character of the political regime has a role to play in how effective the government is in combatting the COVID-19 pandemic. ${ }^{5,12,13}$ Despite their differences, all political systems have legal frameworks for delegation of discretionary authority to executive branches of power during crises, such as the COVID-19 pandemic. However, the functionality of the political apparatus in autocracies and democracies differs, with democracies having a mechanism for checks and balances translating into accountability of those in power. Thus, there is a question of whether authoritarian regimes, with fewer limitations on power, have a higher capacity to respond to the COVID-19 pandemic and whether the adherence to government health guidelines is modified by the public trust in government differently compared with democratic countries.

This study aims to investigate the effect of the stringency of government policies on citizen's compliance and whether the public trust levels amplify this impact on compliance. We will also explore how this effect may vary across the country's political regimes. Furthermore, we hypothesized that high public trust is positively related to compliance with stringent government health guidelines, and people living in countries with a nondemocratic regime have increased adherence to strict government policies. 


\section{Data and Methods}

\section{Data Sources}

We used data from multiple sources in this study. Firstly, we used a large-scale publicly available survey on COVID$19^{14,15}$ attitudes and behavioral measures to examine the connection between public trust and individual compliance to government pandemic policies. The survey was conducted during the first wave of the global spread of COVID-19 between March 20, 2020 and April 7, 2020.

Details on data collection techniques and survey instruments have been previously described in Fetzer et al. ${ }^{14,15}$ Although the survey consisted of more than 111,000 people from 177 countries, we restricted our analysis to observations from only 58 countries with at least 200 participants. Table 1 present the summary characteristics of the 102,627 observations included in this study.

Secondly, we obtained data on COVID-19 government response policies and measures of the strictness of restrictions on people's behavior from the Oxford COVID-19 government response tracker (OxCGRT). ${ }^{16}$ These data allow us to examine the effect of the stringency of government policies on citizen's compliance and whether the public trust levels amplify this impact on compliance. The stringency index comprises information on the level of public information campaigns and implemented closures and containment policies with respect to schools, workplaces, public events, gatherings, public transport, stay-at-home requirements, internal movements, and international travel. The index has a $0-100$ range with higher values representing higher stringency of health guidelines implemented. The OxCGRT data and details on the index calculation are described in Hale et al. ${ }^{16}$ The OxCGRT country-by-day panel is combined with the survey data based on the date when an individual completed the survey and thus reflecting the restrictions and policy environment at that time.

To measure our primary outcome variable - compliance with government restrictions and public health guidelineswe use five questions relating to protective behavior exercised in the past week: (1) stayed at home; (2) not attended social gatherings; (3) kept a two-meter distance from other people; (4) if had symptoms of sickness, would have informed people around; and (5) washed hands more frequently than a month ago. Each of these questions was asked on a scale 0 to 100 , where " 0 " meant the statement did not apply at all and " 100 " applied very much. The perception of public trust was measured by asking the respondents to rate the following questions using a five-point Likert scale with (1) how much they trust their country's government to take care of citizens, and (2)
Table I Summary Statistics for Compliance Index

\begin{tabular}{|c|c|c|c|}
\hline & $\begin{array}{l}\text { No. of } \\
\text { Observations }\end{array}$ & Mean & SD \\
\hline Overall compliance index & 102,627 & 87.05 & 14.18 \\
\hline \multicolumn{4}{|l|}{ Trust in government ${ }^{\mathrm{a}}$} \\
\hline High trust & 45,693 & 87.96 & 13.42 \\
\hline Low trust & 56,934 & 86.31 & 14.72 \\
\hline \multicolumn{4}{|l|}{$\begin{array}{l}\text { Government } \\
\text { truthfulness }^{\mathrm{a}}\end{array}$} \\
\hline High truthfulness & 50,451 & 87.79 & 13.52 \\
\hline Low truthfulness & 52,176 & 86.33 & 14.76 \\
\hline \multicolumn{4}{|l|}{ Gender $^{\mathrm{a}}$} \\
\hline Male & 45,834 & 86.33 & $|4.5|$ \\
\hline Female & 56,793 & 87.62 & 13.89 \\
\hline \multicolumn{4}{|l|}{ Age groups ${ }^{a}$} \\
\hline $18-24$ & 13,037 & 83.48 & 14.80 \\
\hline $25-34$ & 30,098 & 86.32 & 14.15 \\
\hline $35-44$ & 26,803 & 87.84 & 13.93 \\
\hline $45-54$ & 17,974 & 87.75 & 14.00 \\
\hline $55-64$ & 10,516 & 88.98 & 13.61 \\
\hline $65+$ & 4,199 & 90.46 & 13.73 \\
\hline \multicolumn{4}{|l|}{ Income quartiles ${ }^{\mathrm{a}, \mathrm{b}}$} \\
\hline Lowest group & 27,099 & 85.74 & 15.18 \\
\hline Medium lowest & 25,473 & 86.88 & 14.24 \\
\hline Medium highest & 26,166 & 87.49 & 13.65 \\
\hline Highest group & 23,889 & 88.22 & 13.38 \\
\hline \multicolumn{4}{|l|}{ Self-assessed health ${ }^{a}$} \\
\hline Excellent & 30,681 & 88.11 & 13.58 \\
\hline Good & 52,722 & 87.08 & 13.94 \\
\hline Fair & 17,565 & 85.29 & 15.39 \\
\hline Poor & 1,659 & 84.94 & 16.99 \\
\hline \multicolumn{4}{|l|}{ Regime $^{a}$} \\
\hline Anocracy & 9776 & 80.63 & 17.81 \\
\hline Autocracy & 2525 & 87.68 & 13.27 \\
\hline Democracy & 90,326 & 87.72 & 13.58 \\
\hline
\end{tabular}

Notes: a Difference in means of compliance index between groups is significant at I\%. 'Income quartiles are computed using within-country data. We calculate Pearson's correlation coefficients between the compliance index and stringency index (0.20) and between the compliance index and years of education (0.07). Both coefficients are statistically significant at $1 \%$.

how factually truthful they think the government has been about the coronavirus outbreak. We coded the answers to these questions as indicators with " 1 " being assigned if a person reported some or strong level of trust or truthfulness, and "0" otherwise.

\section{Data Analysis}

To estimate the effects of public trust and stringency on people's compliance level, we used linear regression 
models and exploited individual and daily variations in country-level stringency of government public health guidelines. We assumed that each observation is independent and treated daily samples as ordinary cross-sectional data. However, we needed to control the effect of timeand country-level variability on the dependent variable of interest (compliance level). Our baseline model specification is given by:

$$
\begin{array}{r}
y_{i t c}=\alpha_{0}+\alpha_{1} \text { Trust }_{i t c}+\alpha_{2} \text { Stringency }_{t c} \\
+\alpha_{3}\left(\text { Trust }_{i t c} * \text { Stringency }_{t c}\right)+x_{i t c}^{\prime} \beta_{1} \\
+ \text { Time }_{t}^{\prime} \beta_{2}+\text { Country }_{c}^{\prime} \beta_{3}+u_{i t c}
\end{array}
$$

where $y_{i t c}$ is the compliance index calculated for an individual $i$ at day $t$ from country $c$. Trust $t_{i t c}$ and Stringency tc $_{\text {t }}$ represents public trust in government of the individual and stringency index, respectively. We test the amplifying effects of public trust by examining the coefficient $\alpha_{3}$ for the interaction of trust variable and the stringency index. We also include in our regression models the vector $x_{i t c}$ which represents demographic, socioeconomic, and health factors. Previous research on people's compliance with government restrictions during epidemics showed that females and older individuals respected preventative measures more than other groups. ${ }^{3,11}$ We also included a cohort of time $\left(\right.$ Time $\left._{t}\right)$ and country $\left(\right.$ Country $\left._{c}\right)$ fixed effects to account for the potential unobserved differences in compliance between countries and across time and $u_{i t c}$ denotes an error term. Lastly, we examined how the dynamics between public trust, the stringency of restrictions and policy compliance change with respect to political regimes by performing subsample analyses for democracies, anocracies, and autocracies. Our main regression models are estimated using analytical weights in order to improve the representativeness of the sample at the country level. The weights are based on the participant's gender, age, income level, and years of education, see Fetzer et $\mathrm{al}^{14}$ for more details on the construction of the weights. Standard errors were clustered at the country level to accommodate potential within-country correlation structure for the errors.

\section{Results}

Table 1 reports the summary statistics for the compliance index (our outcome variable) by trust, socioeconomic, demographic variables and regime. This preliminary analysis shows that there are statistically significant differences in means of compliance across all characteristics, making them important to include as controls in the regression analysis. For our public trust variables of interest, individuals with high trust in government and those who believe that the government has been truthful about the COVID-19 pandemic have on average higher compliance level. Shown by the correlation between stringency and compliance indices, imposing stricter government regulations corresponds to more responsible behavior. Compliance is also higher on average for females, people with higher income, and in better health. Countries with autocratic and democratic regimes showed higher compliance index on average than anocracies (Table 1 and Figure S1).

Table 2 presents the results of the four regression model specifications. In models 1 and 3, we examine the effects of public trust in government and perceived truthfulness of the government, respectively on compliance. In contrast, in models 2 and 4, we include interaction terms between the stringency index and public trust variables to examine the amplifying effects of public trust with respect to stringency on compliance. Across all models, we find that the effect of stringency of the government restrictions is statistically significant and the imposing of stricter government regulations leads to higher compliance level. For example, mandating the cancellation of public events accounts for an increase in the stringency index by 11 points. This policy change translates to an increase in the predicted compliance level by 1.8 points if the coefficient for the stringency index of 0.162 in models 1 and 3 is used. The magnitude of the 1.8-point increase in compliance index is not trivial and is similar to a person moving from the lowest to the highest income quartile.

In models 1 and 3, the effects of trust in government and truthfulness on compliance, although they showed positive relationship, are statistically insignificant. However, demographic and socioeconomic control variables are generally statistically significant across the models and point in the expected direction with females, older adults, more educated and wealthier individuals reporting higher compliance levels.

In models 2 and 4 , the results suggest that whether individuals exhibit low or high public trust makes a difference in the effectiveness of stringency level on compliance. We found that the impact of stringency on compliance was reinforced by the higher levels of public trust in government and government truthfulness, respectively. Using the Wald test, we also show that including 
Table 2 The Effects on Compliance Index, Estimate (Standard Error)

\begin{tabular}{|c|c|c|c|c|}
\hline & Model I & Model 2 & Model 3 & Model 4 \\
\hline Stringency index & $\begin{array}{l}0.162^{* * *} \\
(0.034)\end{array}$ & $\begin{array}{l}0.117^{* * *} \\
(0.026)\end{array}$ & $\begin{array}{l}0.162 * * * \\
(0.034)\end{array}$ & $\begin{array}{l}0.114 * * * \\
(0.031)\end{array}$ \\
\hline Trust in government & $\begin{array}{l}0.827 \\
(0.913)\end{array}$ & $\begin{array}{l}-6.308^{* * *} \\
(1.597)\end{array}$ & & \\
\hline Stringency index $\times$ trust in government & & $\begin{array}{l}0.105 * * * \\
(0.022)\end{array}$ & & \\
\hline Government truthfulness & & & $\begin{array}{l}0.935 \\
(0.857)\end{array}$ & $\begin{array}{l}-5.522^{* *} \\
(2.182)\end{array}$ \\
\hline Stringency index $\times$ government truthfulness & & & & $\begin{array}{l}0.096 * * * \\
(0.032)\end{array}$ \\
\hline Female & $\begin{array}{l}\text { I.827*** } \\
(0.467)\end{array}$ & $\begin{array}{l}\text { I.806*** } \\
(0.453)\end{array}$ & $\begin{array}{l}\text { I.834*** } \\
(0.469)\end{array}$ & $\begin{array}{l}\text { І.78I*** } \\
(0.457)\end{array}$ \\
\hline Years of education & $\begin{array}{l}0.195 * * \\
(0.091)\end{array}$ & $\begin{array}{l}0.200 * * \\
(0.092)\end{array}$ & $\begin{array}{l}0.194 * * \\
(0.093)\end{array}$ & $\begin{array}{l}0.201 * * \\
(0.092)\end{array}$ \\
\hline \multicolumn{5}{|l|}{ Age (reference: 18-24) } \\
\hline $25-34$ & $\begin{array}{l}2.303^{* * *} \\
(0.916)\end{array}$ & $\begin{array}{l}2.32 I^{* *} \\
(0.895)\end{array}$ & $\begin{array}{l}2.342 * * \\
(0.892)\end{array}$ & $\begin{array}{l}2.314^{* *} \\
(0.907)\end{array}$ \\
\hline $35-44$ & $\begin{array}{l}3.742 * * * \\
(1.248)\end{array}$ & $\begin{array}{l}3.747 * * * \\
(1.216)\end{array}$ & $\begin{array}{l}3.758 * * * \\
(1.253)\end{array}$ & $\begin{array}{l}3.69 * * * \\
(1.186)\end{array}$ \\
\hline $45-54$ & $\begin{array}{l}3.913^{* * *} \\
(0.935)\end{array}$ & $\begin{array}{l}3.957^{* * *} \\
(0.893)\end{array}$ & $\begin{array}{l}3.925 * * * \\
(0.917)\end{array}$ & $\begin{array}{l}3.939 * * * \\
(0.905)\end{array}$ \\
\hline $55-64$ & $\begin{array}{l}6.272 * \\
(0.914)\end{array}$ & $\begin{array}{l}6.392 * \\
(0.866)\end{array}$ & $\begin{array}{l}6.286 * \\
(0.905)\end{array}$ & $\begin{array}{l}6.307^{* * *} \\
(0.866)\end{array}$ \\
\hline $65+$ & $\begin{array}{l}8.133^{* * *} \\
(1.283)\end{array}$ & $\begin{array}{l}8.198 * * * \\
(1.211)\end{array}$ & $\begin{array}{l}8.137 * * * \\
(1.266)\end{array}$ & $\begin{array}{l}8.104 * * * \\
(1.217)\end{array}$ \\
\hline \multicolumn{5}{|l|}{ Income (reference: Ist quartile) } \\
\hline Medium lowest & $\begin{array}{l}1.102 * * \\
(0.440)\end{array}$ & $\begin{array}{l}1.215^{* * *} \\
(0.433)\end{array}$ & $\begin{array}{l}1.092 * * \\
(0.445)\end{array}$ & $\begin{array}{l}\text { I.I } 77 * * * \\
(0.444)\end{array}$ \\
\hline Medium highest & $\begin{array}{l}0.206 \\
(0.579)\end{array}$ & $\begin{array}{l}0.399 \\
(0.555)\end{array}$ & $\begin{array}{l}0.213 \\
(0.599)\end{array}$ & $\begin{array}{l}0.371 \\
(0.585)\end{array}$ \\
\hline Highest group & $\begin{array}{l}\text { I.633*** } \\
(0.495)\end{array}$ & $\begin{array}{l}\text { I.848*** } \\
(0.475)\end{array}$ & $\begin{array}{l}\text { I.639*** } \\
(0.50 \mathrm{I})\end{array}$ & $\begin{array}{l}\text { I.798*** } \\
(0.494)\end{array}$ \\
\hline \multicolumn{5}{|l|}{ Health (reference: poor health) } \\
\hline Fair & $\begin{array}{l}-1.123 \\
(1.292)\end{array}$ & $\begin{array}{l}-1.247 \\
(1.289)\end{array}$ & $\begin{array}{l}-1.172 \\
(1.283)\end{array}$ & $\begin{array}{l}-1.214 \\
(1.285)\end{array}$ \\
\hline Good & $\begin{array}{l}1.029 \\
(1.391)\end{array}$ & $\begin{array}{l}0.924 \\
(1.392)\end{array}$ & $\begin{array}{l}0.989 \\
(1.365)\end{array}$ & $\begin{array}{l}0.882 \\
(1.379)\end{array}$ \\
\hline Excellent & $\begin{array}{l}1.020 \\
(1.799)\end{array}$ & $\begin{array}{l}0.913 \\
(1.759)\end{array}$ & $\begin{array}{l}0.980 \\
(1.793)\end{array}$ & $\begin{array}{l}0.857 \\
(1.749)\end{array}$ \\
\hline Wald test for interaction $\chi^{2}$ statistic ( $p$-value) & NA & $23.20(0.00)$ & NA & $9.05(0.00)$ \\
\hline
\end{tabular}

Notes: Total number of observations is 102,627 . Standard errors are clustered at country level. ***Significant at $1 \%$. **Significant at $5 \%$. 
interaction terms in models 2 and 4 significantly improves the fit of the models in comparison to models 1 and 3 .

Figure $1 \mathrm{~A}$ and $1 \mathrm{C}$ shows that the marginal impact of stringency has a greater effect on compliance for individuals with high trust. The slope of the regression line for the high trust group is 0.222 (95\%CI: $0.155-0.289$ ] and is almost twice that of the low trust group 0.117 (95\%CI: $0.065-$ $0.170)$. Figure $1 \mathrm{~B}$ and $1 \mathrm{D}$ provides important evidence that these differences between low and high trust groups are only statistically significant at the low and high stringency levels as the slopes for high and low trust groups intersect. Thus, the predicted compliance for the high trust in government group is higher than for the low trust in government group at stringency values of 75 and above. In comparison, the compliance is higher for the low trust group at the stringency index of 40 and below. A similar pattern of interaction effects is also present for the government truthfulness variable.

The results in Table 3 suggest that the effect of public trust in government in autocracy regimes on people's compliance increases with an increase in stringency level

A

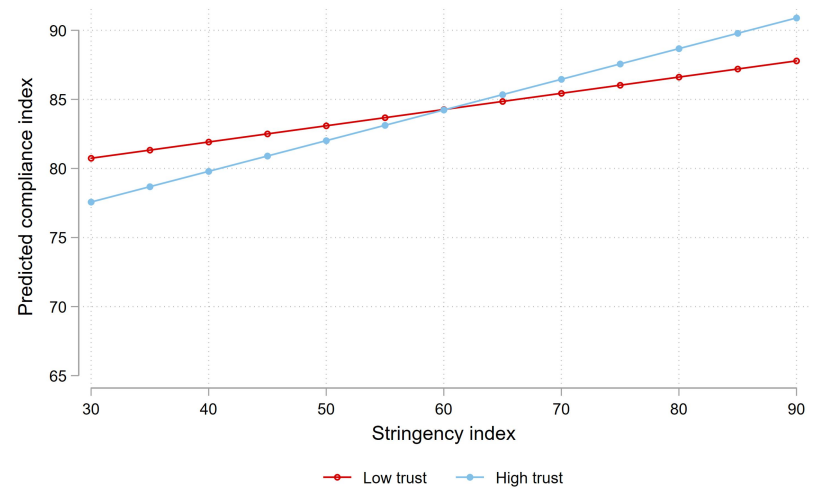

C

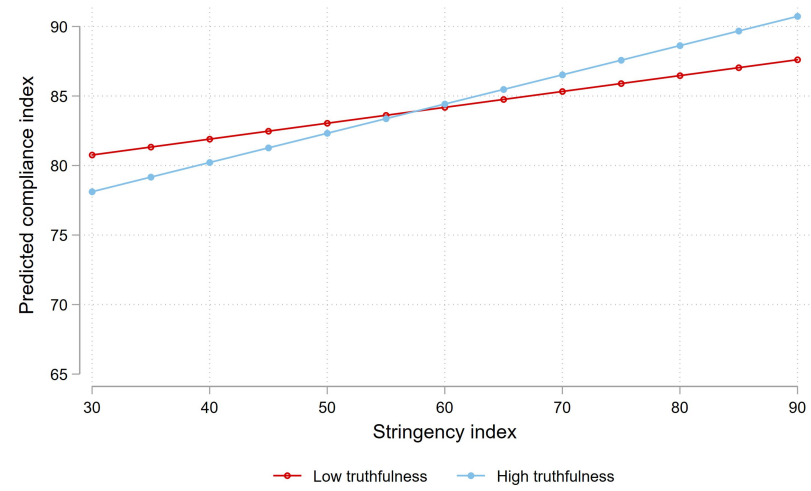

of restrictive government measures. The high trust group in Figure 2A consistently shows higher values than the low trust group across the range of stringency values. The differences in average marginal effects (AMEs) between high and low trust groups in Figure 2B are statistically significant and increase with stringency from 3.2 to 5.3 points in predicted compliance. This amplification of stringency effect on compliance due to the trust in government is not trivial considering that the impact of being a female (one of the common predictors found in the literature) is associated with 1.8-2.0 increase in compliance.

For democratic countries, Table 3 and Figure $2 \mathrm{E}$ and $2 \mathrm{~F}$ suggest that public trust compounds the effect of strict restrictions on compliance. Similar to the main results in Table 2, low trust individuals show higher predicted compliance when the policies are less restrictive than the high trust group. However, the reverse is true once more stringent restrictions are implemented. The results for countries who are in the middle of the political regime spectrum (ie anocracies), the impact of stringency index on compliance

\section{B}

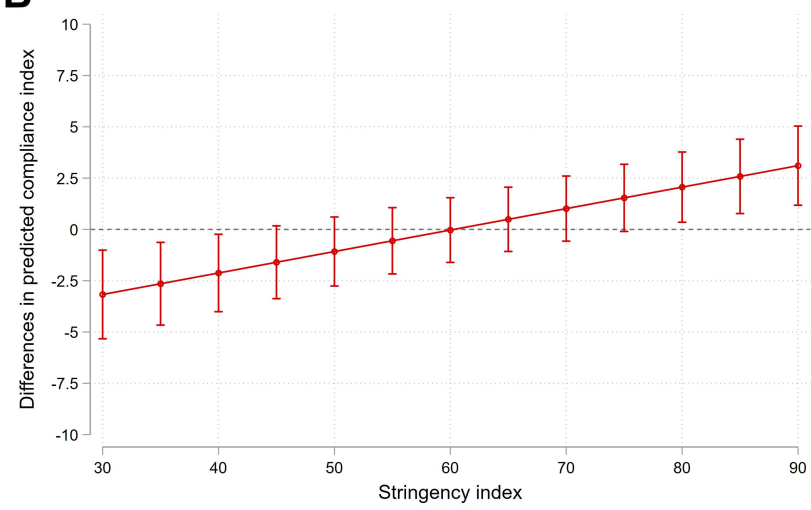

D

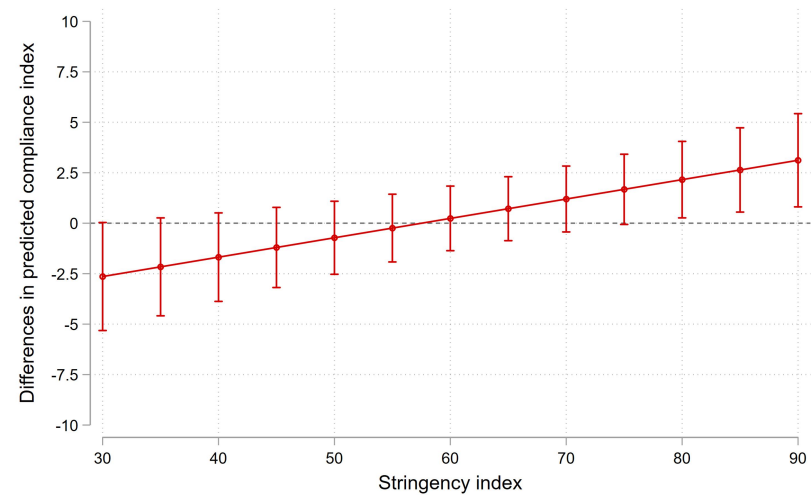

Figure I Amplifying effects of trust and stringency on compliance. (A) The impact of restrictions on compliance. (B) Differences between AMEs and government trust levels on compliance. (C) The impact of restrictions and truthfulness on compliance. (D) Differences in AMEs between government truthfulness levels on compliance. 
Table 3 The Heterogeneous Effects on Compliance by the Political Regime

\begin{tabular}{|l|l|l|l|}
\hline & Autocracy & Anocracy & Democracy \\
\hline Stringency index & $\begin{array}{l}0.007 \\
(0.026)\end{array}$ & $\begin{array}{l}0.365^{* * *} \\
(0.081)\end{array}$ & $\begin{array}{l}0.098 * * * \\
(0.025)\end{array}$ \\
\hline Trust in government & $2.206 * *$ & 4.386 & $-7.436 * * *$ \\
$(0.501)$ & $(3.119)$ & $(2.066)$ \\
\hline Stringency index $\times$ trust in government & $0.034^{*}$ & -0.050 & $0.109 * * *$ \\
& $(0.010)$ & $(0.046)$ & $(0.027)$ \\
\hline Wald test for interaction (p-value) & $12.43(0.07)$ & $\begin{array}{l}1.21(0.31) \\
9776\end{array}$ & $\begin{array}{l}16.85(0.00) \\
90,326\end{array}$ \\
\hline No. of observations & 2525 & 9776 & \\
\hline
\end{tabular}

Notes: All models include fixed effects (time and country), and individual controls such as gender, age, years of education, income level, and self-assessed health. Standard errors are clustered at country level. *** Significant at $1 \%$, **significant at $5 \%$, *significant at $10 \%$.

is not heterogeneous with respect to the trust in government variable (see Figure 2C and 2D).

\section{Discussion}

The high burden associated with the highly contagious COVID-19 disease cannot be overemphasized; there is a benefit when the public complies with public health guidelines. However, policy compliance is not without cost. Stringent restrictions, such as lockdown orders and school closures, may bring not only work but also social life disruptions that affect people's mental health ${ }^{17-19}$ and negative economic and financial consequences on micro and macro levels. ${ }^{20,21}$ Previous studies have shown the importance of public trust on the effectiveness of government restrictions. ${ }^{22}$ We contribute to the literature by providing empirical evidence that an increase in public trust during the onset of COVID-19 pandemic significantly amplifies citizen's compliance with an increased level of government stringent public health policies. The impact of strict measures on compliance is twice as large for individuals with high trust in government than for those with low trust; however, when governments measures are less restrictive, individuals with lower trust level are more likely to comply.

We posit that this asymmetry in response could be influenced by the way individuals view the merits of the restrictions conditional on their underlying trust attitudes towards government and its institutions. In the situation of high uncertainty, especially during the onset of COVID-19 pandemic, the higher the predicted compliance at low levels of restrictions by people with low trust is not surprising. This can be potentially viewed as a self-protective behavior in response to the perception that the government is not implementing a suitable level of restrictions or has not been truthful with them about COVID-19. Conversely, if an individual generally believes that the government acts in the best interests of the people, the compliance to the restrictions is likely to be positively reinforced.

Public distrust in government may lead to a lower level of compliance with government measures and thus, unsuccessful public health interventions..$^{3,5,11,23}$ For example, Goldstein and Wiedemann ${ }^{5}$ reported that higher political and social trust measures are associated with improvements in compliance with stay-at-home orders in the US. The authors underscored the importance of trust in state capacity and the different levels of trust resulting in asymmetrical compliance, compounded by partisanship behavior. $^{5}$ In Nigeria, large-scale political distrust due to corruption was said to undermine public adherence to government COVID-19 policies. $^{23}$ A study by Lalot et al revealed that absence of concern and trust significantly reduce people's compliance with restrictive government measures put in place in Italian and French cities. ${ }^{24}$ This is also consistent with the findings among young Swiss adults. $^{25}$

Furthermore, in situations when the majority of the population comply with government restrictions and public health advice, the created public good and incentives will extend to free-riders as well. In other words, some individuals (noncompliers) enjoy the benefits of public health practices without respecting them. As in other free-riding problems, the prolonged noncompliance reduces the benefits of cooperative behaviors of the compliers, and in the case of epidemics, leads to a spike in new infections. To mitigate this problem, governments can penalise noncompliers, thus making the incentive to 
A

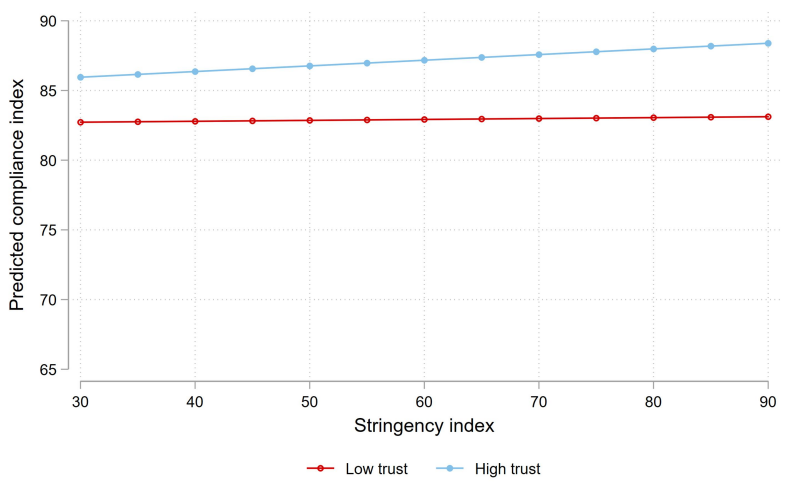

C

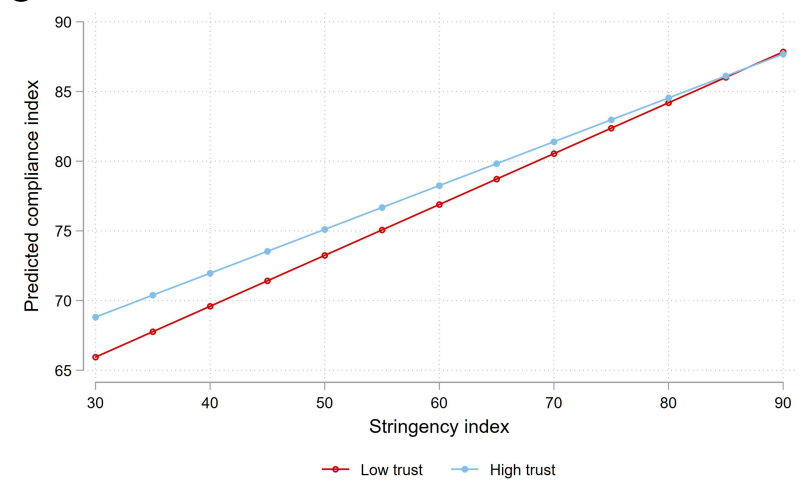

$\mathbf{E}$

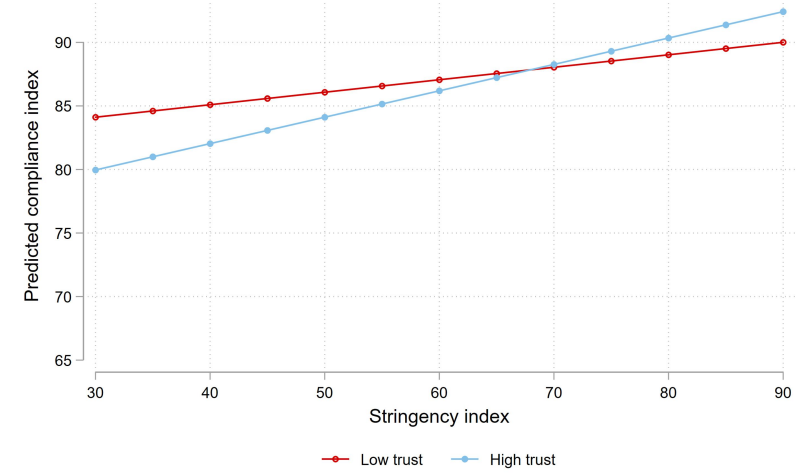

B

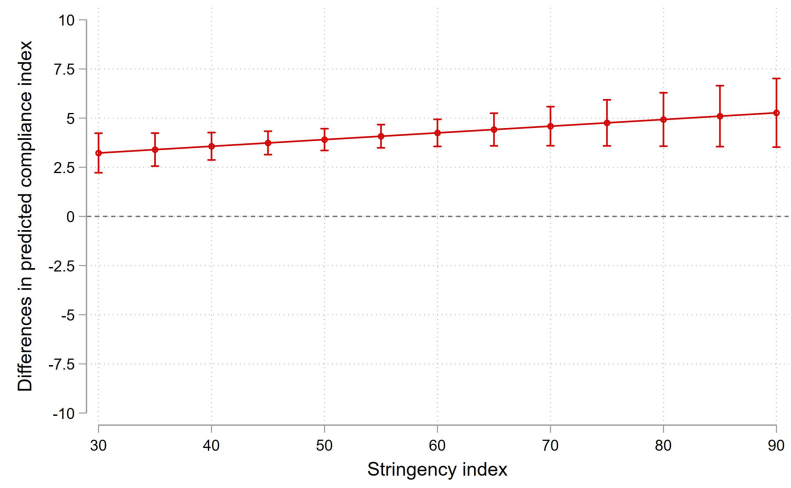

D

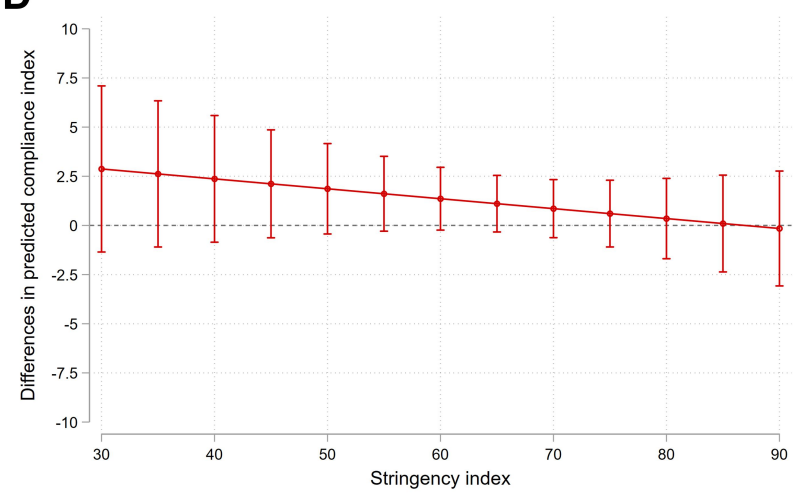

$\mathbf{F}$

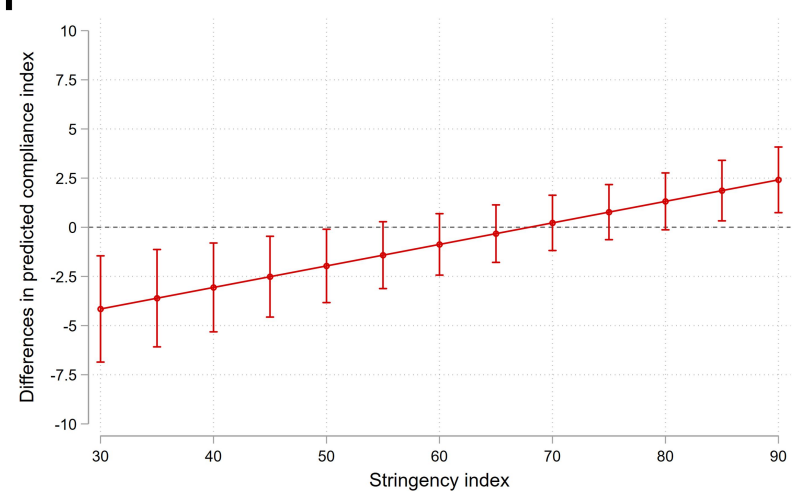

Figure 2 Amplifying effects of trust and stringency on compliance by political regime. The impact of restrictions on compliance for (A) autocracy, (C) anocracy, and (E) democracy regimes, respectively. Differences in AMEs between government trust levels on compliance for (B) autocracy, (D) anocracy, and (F) democracy, regimes, respectively.

free-riders smaller. However, enforcement of the penalties may be costly and problematic if the number of noncomplying individuals is considerable. A better public policy approach is through education and transparent communication about the public health crisis aiming to reinforce good behavior. This also underscores the value of political and social trust in achieving the goal of high compliance.
Our analysis also revealed that compliance is higher for females, elderly and people with higher income and in better health. Previous research on people's compliance with government restrictions during epidemics showed that females and elderly respected preventative measures more than other groups. ${ }^{3,11,26}$ Perhaps the fear of being infected incentivizes individuals, especially those who are vulnerable, to change their behavior and comply with 
public health advice. ${ }^{1,2}$ As the risk for severe illness from COVID-19 is the highest for older adults, ${ }^{27,28}$ it is not surprising to find that this group has been associated with greater compliance and the incremental increase in compliance across a broad age range mirrors the evidence that the risk for severe illness and mortality from COVID19 increases with age. Our results are consistent with findings from an ongoing longitudinal cohort study of young adults conducted during the early stage of the COVID-19 pandemic in Switzerland revealed that younger adults were less likely to comply with Swiss government public health guidelines. ${ }^{25}$

We also found these dynamics between public trust, the stringency of restrictions, and policy compliance to be heterogeneous between political regimes. In democracies, people who have high trust in the government have lower infection avoidance behavior when the government does not call for it, whereas they have higher infection avoidance behavior when the government does call for it. This is not true in autocracies or anocracies, in which government-trusting individuals always tend to have higher infection avoidance behaviors. Perhaps this suggests greater reliance and trust in both low-risk messages and highrisk messages from the government in democracies.

This study has a number of limitations. Firstly, it was based on survey data sets conducted during the onset of the COVID-19 pandemic, and there could be an overrepresentation of individuals who were likely more concerned with the spread of the disease. Secondly, there are response bias concerns, particularly social desirability bias, which might have led to the underreporting of noncompliance behavior. However, this might be less of a problem as individuals self-completed the questionnaire anonymously and via an online channel which helps to elicit true preferences and answers. ${ }^{29}$

In summary, we have shown how important it is for a government to build and maintain public trust and citizens' cooperation in managing public health response. The COVID-19 pandemic has not only brought significant health and economic challenges around the world, but also provided an opportunity for governments to restore and strengthen trust at a time when it is most needed. Moreover, as the number of new infections stabilizes, public trust will be among the crucial factors for recovery on the other side. Our findings indicate that public trust is strongly associated with compliance and amplifies the impact of the government preventative measures. Yet, the dynamics of this amplification differs among political regimes.

\section{Disclosure}

The authors report no conflicts of interest in this work.

\section{References}

1. Wise T, Zbozinek TD, Michelini G, Hagan CC, Mobbs D. Changes in risk perception and self-reported protective behaviour during the first week of the COVID-19 pandemic in the United States. $R$ Soc Open Sci. 2020;7(9):200742. doi:10.1098/rsos.200742

2. Reynolds DL, Garay JR, Deamond SL, Moran MK, Gold W, Styra R. Understanding, compliance and psychological impact of the SARS quarantine experience. Epidemiol Infect. 2008;136(7):997-1007. doi:10.1017/S0950268807009156

3. Almutairi AF, BaniMustafa A, Alessa YM, Almutairi SB, Almaleh Y. Public trust and compliance with the precautionary measures against COVID-19 employed by authorities in Saudi Arabia. Risk Manag Healthc Policy. 2020;13:753-760. doi:10.2147/RMHP.S257287

4. Blair RA, Morse BS, Tsai LL. Public health and public trust: survey evidence from the ebola virus disease epidemic in Liberia. Soc Sci Med. 2017;172:89-97. doi:10.1016/j.socscimed.2016.11.016

5. Goldstein D, Wiedemann J. Who Do You Trust? The Consequences of Political and Social Trust for Public Responsiveness to COVID-19 Orders. 2020.

6. Henderson J, Ward PR, Tonkin E, et al. Developing and maintaining public trust during and post-COVID-19: can we apply a model developed for responding to food scares? Front Public Health. 2020;8:369. doi:10.3389/fpubh.2020.00369

7. Dalton RJ. Democratic Challenges. Democratic Choices: The Erosion of Political Support in Advanced Industrial Democracies. Oxford University Press; 2004.

8. Marien S, Hooghe M. Does political trust matter? An empirical investigation into the relation between political trust and support for law compliance. Eur J Polit Res. 2011;50(2):267-291. doi:10.1111/ j.1475-6765.2010.01930.x

9. Wellcome Global Monitor. How Does the World Feel About Science and Health. Wellcome Global Monitor; 2019.

10. Vinck P, Pham PN, Bindu KK, Bedford J, Nilles EJ. Institutional trust and misinformation in the response to the 2018-19 ebola outbreak in North Kivu, DR Congo: a population-based survey. Lancet Infect Dis. 2019;19(5):529-536. doi:10.1016/S1473-3099(19)30063-5

11. Clark C, Davila A, Regis M, Kraus S. Predictors of COVID-19 voluntary compliance behaviors: an international investigation. Global Transitions. 2020;2:76-82. doi:10.1016/j.glt.2020.06.003

12. Flinders M. Democracy and the politics of coronavirus: trust, blame and understanding. Parliam Aff. 2020. doi:10.1093/pa/gsaa013

13. Greer SL, King EJ, da Fonseca EM, Peralta-Santos A. The comparative politics of COVID-19: the need to understand government responses. Glob Public Health. 2020;15(9):1413-1416. doi:10.1080/ 17441692.2020.1783340

14. Fetzer T, Witte M, Hensel L, et al. Global Behaviors and Perceptions in the COVID-19 Pandemic. 2020. Available from: https://doi.org/10. $31234 /$ osf.io/ $3 \mathrm{kfmh}$.

15. Fetzer TR, Witte M, Hensel L, et al. Global Behaviors and Perceptions at the Onset of the COVID-19 Pandemic. National Bureau of Economic Research; 2020:0898-2937.

16. Hale T, Angrist N, Emily Cameron-Blake N, et al. Oxford COVID-19 Government Response Tracker. Blavatnik School of Government; 2020.

17. Terry PC, Parsons-Smith RL, Terry VR. Mood responses associated with COVID-19 restrictions. Front Psychol. 2020;11:3090. doi:10.3389/fpsyg.2020.589598 
18. Van Rheenen TE, Meyer D, Neill E, et al. Mental health status of individuals with a mood-disorder during the COVID-19 pandemic in Australia: initial results from the COLLATE project. $J$ Affect Disord. 2020;275:69-77. doi:10.1016/j.jad.2020.06.037

19. Mækelæ MJ, Reggev N, Dutra N, et al. Perceived efficacy of COVID-19 restrictions, reactions and their impact on mental health during the early phase of the outbreak in six countries. $R$ Soc Open Sci. 2020;7(8):200644. doi:10.1098/rsos.200644

20. Pak A, Adegboye OA, Adekunle AI, Rahman KM, McBryde ES, Eisen DP. Economic consequences of the COVID-19 outbreak: the need for epidemic preparedness. Front Public Health. 2020;8:241. doi:10.3389/fpubh.2020.00241

21. Bonaccorsi G, Pierri F, Cinelli M, et al. Economic and social consequences of human mobility restrictions under COVID-19. Proc Natl Acad Sci U S A. 2020;117(27):15530-15535. doi:10.1073/pnas.2007658117

22. Bargain O, Aminjonov U. Trust and Compliance to Public Health Policies in Times of COVID-19. 2020.

23. Ezeibe CC, Ilo C, Ezeibe EN, et al. Political distrust and the spread of COVID-19 in Nigeria. Glob Public Health. 2020;1-14.

24. Lalot F, Heering MS, Rullo M, Travaglino GA, Abrams D. The dangers of distrustful complacency: low concern and low political trust combine to undermine compliance with governmental restrictions in the emerging Covid-19 pandemic. Group Process Intergroup Relat. 2020. doi:10.1177/1368430220967986.
25. Nivette A, Ribeaud D, Murray A, et al. Non-compliance with COVID-19-related public health measures among young adults in Switzerland: insights from a longitudinal cohort study. Soc Sci Med. 2020;268:113370. doi:10.1016/j.socscimed.2020.113370

26. Sobol M, Blachnio A, Przepiórka A. Time of pandemic: temporal perspectives related to compliance with public health regulations concerning the COVID-19 pandemic. Soc Sci Med. 2020;265:113408. doi:10.1016/j.socscimed.2020.113408

27. Bialek S, Boundy E, Bowen V, COVID TC, Team R. Severe outcomes among patients with coronavirus disease 2019 (COVID-19)United States, february 12-march 16, 2020. MMWR Morb Mortal Wkly Rep. 2020;69(12):343-346. doi:10.15585/mmwr.mm6912e2

28. Nikolich-Zugich J, Knox KS, Rios CT, Natt B, Bhattacharya D. SARS-CoV-2 and COVID-19 in older adults: what we may expect regarding pathogenesis, immune responses, and outcomes. Geroscience. 2020;1-10.

29. Krumpal I. Determinants of social desirability bias in sensitive surveys: a literature review. Qual Quant. 2013;47(4):2025-2047. doi:10.1007/s11135-011-9640-9
Risk Management and Healthcare Policy

\section{Publish your work in this journal}

Risk Management and Healthcare Policy is an international, peerreviewed, open access journal focusing on all aspects of public health, policy, and preventative measures to promote good health and improve morbidity and mortality in the population. The journal welcomes submitted papers covering original research, basic science, clinical \& epidemiological studies, reviews and evaluations,

\section{Dovepress}

guidelines, expert opinion and commentary, case reports and extended reports. The manuscript management system is completely online and includes a very quick and fair peer-review system, which is all easy to use. Visit http://www.dovepress.com/testimonials.php to read real quotes from published authors. 